Review Article

\title{
The Regularity of the Site of Impaction in Recurrent Gallstone Ileus: A Systematic Review and Meta-Analysis of Reported Cases
}

\author{
Nasser A. N. Alzerwi $\mathbb{D}^{1},{ }^{1}$ Bandar Idrees, ${ }^{2}$ Saeed Alsareii, ${ }^{3}$ Yaser Aldebasi, ${ }^{4}$ \\ and Afnan Alsultan 5 \\ ${ }^{1}$ Department of Surgery, College of Medicine, Majmaah University, Ministry of Education, Al-Majmaah City, 11952, \\ P.O. Box 66, Riyadh, Saudi Arabia \\ ${ }^{2}$ Gastrointestinal, Biliopancreatic, and Minimally Invasive Surgery at Department of Surgery, \\ Prince Sultan Military Medical City in Riyadh, Makkah Al Mukarramah Rd, As Sulimaniyah, Riyadh 12233, Saudi Arabia \\ ${ }^{3}$ Department of Surgery, College of Medicine, Najran University, Najran, Saudi Arabia \\ ${ }^{4}$ Board Certified General Surgeon, Department of Surgery, King Salman Hospital in Riyadh, Riyadh, Saudi Arabia \\ ${ }^{5}$ Resident in Training, Department of Surgery, King Saud Medical City, Riyadh, Saudi Arabia
}

Correspondence should be addressed to Nasser A. N. Alzerwi; n.alzerwi@mu.edu.sa

Received 18 February 2021; Revised 18 August 2021; Accepted 16 November 2021; Published 2 December 2021

Academic Editor: Xingshun Qi

Copyright (C) 2021 Nasser A. N. Alzerwi et al. This is an open access article distributed under the Creative Commons Attribution License, which permits unrestricted use, distribution, and reproduction in any medium, provided the original work is properly cited.

\begin{abstract}
Objective. Due to the rarity of recurrent gallstone ileus (RGSI), its epidemiological and clinical features are elusive. With a focus on mortality and the site of impaction, this study consolidates the key clinical characteristics of index GSI (IGSI) and RGSI. Methods. A meta-analysis of cases reported on RGSI was performed. Risk factors for mortality and site of impaction were examined, and a subgroup analysis was performed for age, sex, and site of impaction (jejunum, ileum, or others). Results. In the final analysis, 50 ( 56 individual cases) studies were included. The paired data for the site of impaction was available for 45 patients. Women accounted for $87.3 \%$ of all RGSI cases included in the pooled analysis. The median age (interquartile range, IQR) of the patients was 70 (63-76) years, and the median time of recurrence (IQR) was 20.5 (8.5-95.5) days. The overall mortality rate was $11.8 \%$, without correlation between the mortality rate and age, the time of recurrence, or the site of impaction. The region in which the stone was found in RGSI and IGSI was similar in most cases $(p=0.002)$. Logistic regression also revealed a higher probability of stone impaction in the ileum in RGSI if it was the site of impaction in IGSI. In most cases, enterolithotomy was the preferred method. Conclusions. A high index of suspicion for RGSI should be maintained for older women with a history of GSI. The region where the stone was impacted during IGSI should be investigated first in such patients.
\end{abstract}

\section{Introduction}

Gallstone ileus (GSI) is a severe complication of cholelithiasis in which a stone enters the enteric lumen and causes mechanical obstruction [1-3]. Recurrent gallstone ileus (RGSI) occurs in $5-8 \%$ of patients with GSI [4]. The stone responsible for RGSI can emanate from an untreated biliaryenteric fistula with cholelithiasis, or it could be a gallstone that was not removed at the time of index operation [5]. RGSI increases the clinical dilemmas associated with the treatment of GSI, as the patient is now at increased risk and the prevention of further recurrences is a high priority [6].
The potential variables associated with RGSI are unknown mainly due to the lack of prospective or retrospective studies. However, fortunately, there are several case studies available that provide information on the demographic and clinical characteristics of RGSI and might be helpful in clinical decision-making [4-11]. In a significant attempt to clarify the clinical characteristics of patients with RGSI, Mir et al. [12] conducted a systematic review of the cases reported in the literature up to 2015. Although these authors provided a highly comprehensive and critical overview of the demographic and clinical characteristics of RGSI, their work did not report data synthesis and subgroup analysis. 
The objective of this meta-analysis was to compile important clinical and demographic characteristics of patients with RGSI, both in index GSI (IGSI), that is, the first episode of GSI and in RGSI, and to examine the factors associated with mortality and SOI.

\section{Methods}

This review was conducted in accordance with the Preferred Reporting Items for Systematic Review and Meta-Analyses (PRISMA) guidelines (Table S1) [13]. As there were no prospective or retrospective studies or clinical trials on RGSI, the focus was on case reports and case series $[14,15]$. The inclusion criteria were primarily based on the fact that the case must have a confirmed diagnosis of RGSI. Data elements such as (i) SOI in IGSI and RGSI, (ii) size of stone in IGSI and in RGSI, (iii) number of stones in IGSI and in RGSI, (iv) symptoms of RGSI, (v) time duration between IGSI and RGSI, (vi) predisposing factors, (vii) diagnosis modality (s), (viii) management strategies during IGSI and at RGSI, and (ix) complications/adverse events in RGSI (x) mortality were given high priority in the analysis. The SOI at IGSI was referred to as ISOI, whereas the SOI at RGSI was referred to as RSOI. Conference/symposium abstracts, letters to the editors, cases with incomplete descriptions, reviews, or case series with aggregate data with incomplete information on individual cases were excluded.

2.1. Search Strategies and Information Sources. A systematic search of key terms was carried out in the Scopus, Web of Science (WOS), PubMed, and Cochrane databases. The search was completed on July 14, 2020 (Table S2). The search terms used were the combination of "intestinal obstruction," "gallstone," or "GSI," and "recurrent" or "recurrence." Reference lists of the selected articles were also examined to find other relevant articles.

2.2. Study Selection and Definitions. The authors independently conducted the database search (NR and BI), with the initial results imported and processed using reference management software. All duplicates were removed first, and then the titles and abstracts of the articles were examined. The authors retrieved the full texts of the relevant articles and independently evaluated them (NR, BI, SA, and AA). Data were extracted using a standardized form containing 25 variables related to IGSI and RGSI. Data elements extracted included country, publication year, demographic data, comorbidities, diagnosis, SOI, and hospital mortality. Depending on the anatomical location, the SOI was divided into three broader categories: jejunum, ileum (ileum or ileocecal valve), and others. RGSI was defined as the intraoperatively/radiologically confirmed recurrence of intestinal obstruction by a gallstone. A faceted stone is one that has at least one flattened side. Multiple stones are defined by the presence of more than one stone; in the analyses, the number of stones was stratified as a single stone, two stones, or more than two stones. The duration of the symptoms was defined as the duration from the onset of the symptom to hospital admission. Recurrence time was defined as the duration in days between discharge after IGSI and readmission for RGSI; when RGSI occurred before discharge, the time difference between index episode and RGSI was considered recurrence time. Large stones were defined as having at least one dimension greater than $3 \mathrm{~cm}[16,17]$. Mortality was defined as the percentage of patients who died in a particular group.

2.3. Summary Measures and Statistical Analysis. The characteristics of the patients and surgical details were descriptively summarized. Statistical significance of categorical variables was examined by the chi-square test or Fischer's exact test and of continuous variables by the Wilcoxon, Mann-Whitney, or Kruskal-Wallis test. The risk factors for mortality and SOI in RGSI were analyzed using exploratory univariate and stepwise multivariate logistic regression. Subgroup analysis was also performed with respect to age, SOI, and sex. A $p$ value of $<0.05$ was considered statistically significant. Missing data were excluded from the respective analysis, and the total number of cases available for each analysis was provided as the denominator; for example, in $16 / 47,47$ represents the total number of patients for whom the respective information was available.

\section{Results}

3.1. Study Selection, Completeness of Data, and Demographics. In total, 1190 articles were obtained after the database search, and 45 additional records were identified after the screening of references; of these, 50 (56 individual cases) were included in the final analysis (Figure 1) $[1,5-8,11,18-61]$. The data extraction efficiency for key variables was $89.9 \%$ (Figure 2 ).

3.2. IGSI: Clinical Characteristics and Management. In IGSI, the ileum was reported to be the most common SOI (Table 1), representing $61.7 \%$ (29/47) of all cases, followed by the jejunum $(16 / 47,34.0 \%)$ and others $(2 / 47,4.3 \%)$. For 33 patients, information on the size of the stone was available. In IGSI, a large primary stone (size $\geq 3 \mathrm{~cm}$ ) was observed in $75.8 \%$ of patients (25/33). Only 18 cases explicitly specified the presence or absence of a faceted stone, and $66.7 \%$ of such cases (12/18) mentioned the occurrence of a faceted stone; however, the faceted stone in IGSI was not exclusively assigned as the cause of RGSI in most cases. In IGSI, the status of multiple stones was reported in 52 cases, with only 3 $(3 / 52,5.8 \%)$ of them having more than two stones.

Operative details of IGSI were available for 51 patients. Enterolithotomy alone was performed in $82.4 \%(42 / 51)$ of IGSI cases, enterolithotomy + segmental resection was used in $5(5 / 51,9.8 \%)$ patients $[7,18,21,24]$, and other interventions were used in only $4(4 / 51,7.8 \%)$ cases $[20,54,61]$.

3.3. Time of Recurrence. The time of recurrence was evaluated as a function of the number of stones, the size of the stones, the age, and ISOI to determine whether any clinical 


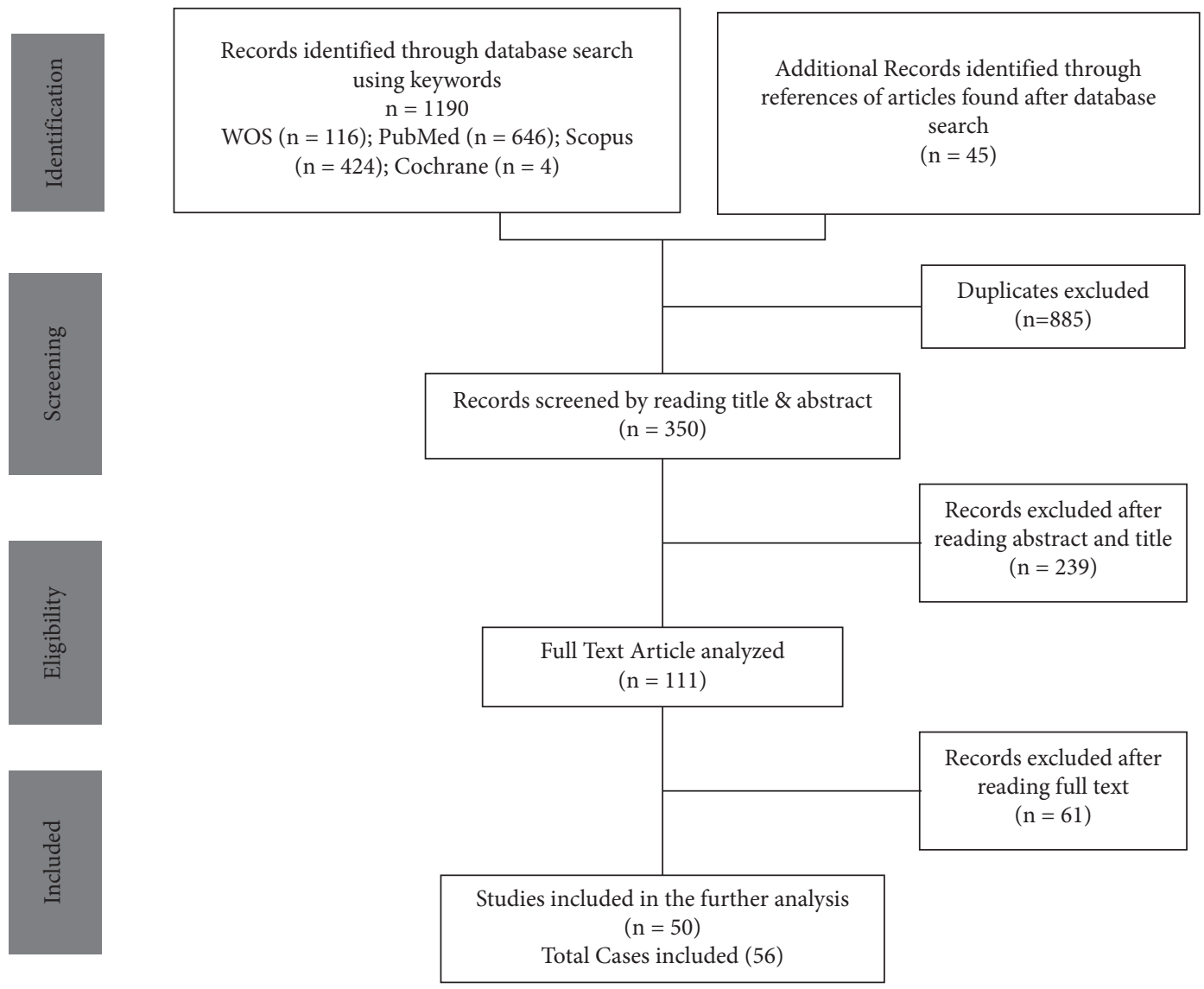

Figure 1: Flow diagram used for data extraction.

manifestations of IGSI affect the time of recurrence (Figure 3). The median recurrence time (interquartile range, IQR) was 20.5 (8.5-95.5) days (Table 1; Figure S1). ISOI or the number of stones at IGSI did not have a statistically significant effect on the recurrence time (Table 2; Figures 3(a) and 3(b)). There were no statistically significant differences in the time of recurrence between patients of different ages $(p=0.96$, Figure $3(c))$. The time of recurrence in patients with large stones was not statistically different from that in patients with smaller stones $(p=0.18$, Figure 3(d)). To eliminate the outlier effect, this study did not include the time of recurrence of more than 100 days. The association between age and time of recurrence was also investigated, but no correlation was found $(r=0.02$, $p=0.97$, Figure S2).

3.4. RGSI: Clinical Characteristics and Management. The ileum was the most common SOI in RGSI, accounting for $62.0 \%$ of patients $(31 / 50)$, and the jejunum was the SOI in 15 $(15 / 50,30.0 \%)$ patients (Table 1$)$. Other SOIs were the duodenum [31] and the rectum [56,57], represented in 1 and 3 cases, respectively. The median age was 70 years (interquartile range (IQR): 63-76 years), and 48/55 (87.3\%) were women (Table 1). Most of the patients had symptoms such as abdominal pain, vomiting, or nausea. The median duration of symptoms was 2.5 (1.0-7.0) days. Patients reported abdominal discomfort, vomiting, and nausea in 93.6\% (44/47), 80.9\% (38/ $47)$, and $34.0 \%(16 / 47)$ of the cases, respectively. Operative details for the treatment of RGSI were available for 53 patients. In $79.2 \%$ of the patients $(42 / 53)$, enterolithotomy was the surgical method. In 5 patients $(5 / 53,9.4 \%)$, enterolithotomy + cholecystectomy was performed [7, 18, 29, 32, 36] and enterolithotomy + segmental resection was used only in 2 $(2 / 53,3.8 \%)$ cases $[33,44]$. Nonsurgical management was used in $4(4 / 53,7.5 \%)$ cases $[20,31,56,57]$. The overall mortality rate was $11.8 \%(6 / 51)$. Five of the six deaths occurred after an enterolithotomy; however, in terms of mortality, there were no statistically significant differences between patients with RGSI who underwent different surgical procedures $(p=0.32$, Table S3). In $28.3 \%$ (13/46) of the cases, postoperative complications were observed. There was no statistically significant difference in the frequency of complications among patients with RGSI who underwent different surgical procedures ( $p=0.17$, Table S3). Predictors of mortality in RGSI were investigated using univariate logistic regression; however, no statistically significant variables were identified (Table S4).

RGSI was not observed in patients under 40 years of age (Table S5). In fact, only 2 (3.6\%) patients were between the ages of 41 and 50 years. The 51-60-year-old age group represented $18.2 \%$ of all patients. More than $75 \%$ of the patients were older than 60 years. Furthermore, no significant differences in clinical characteristics were found between men and women (Table S6). 


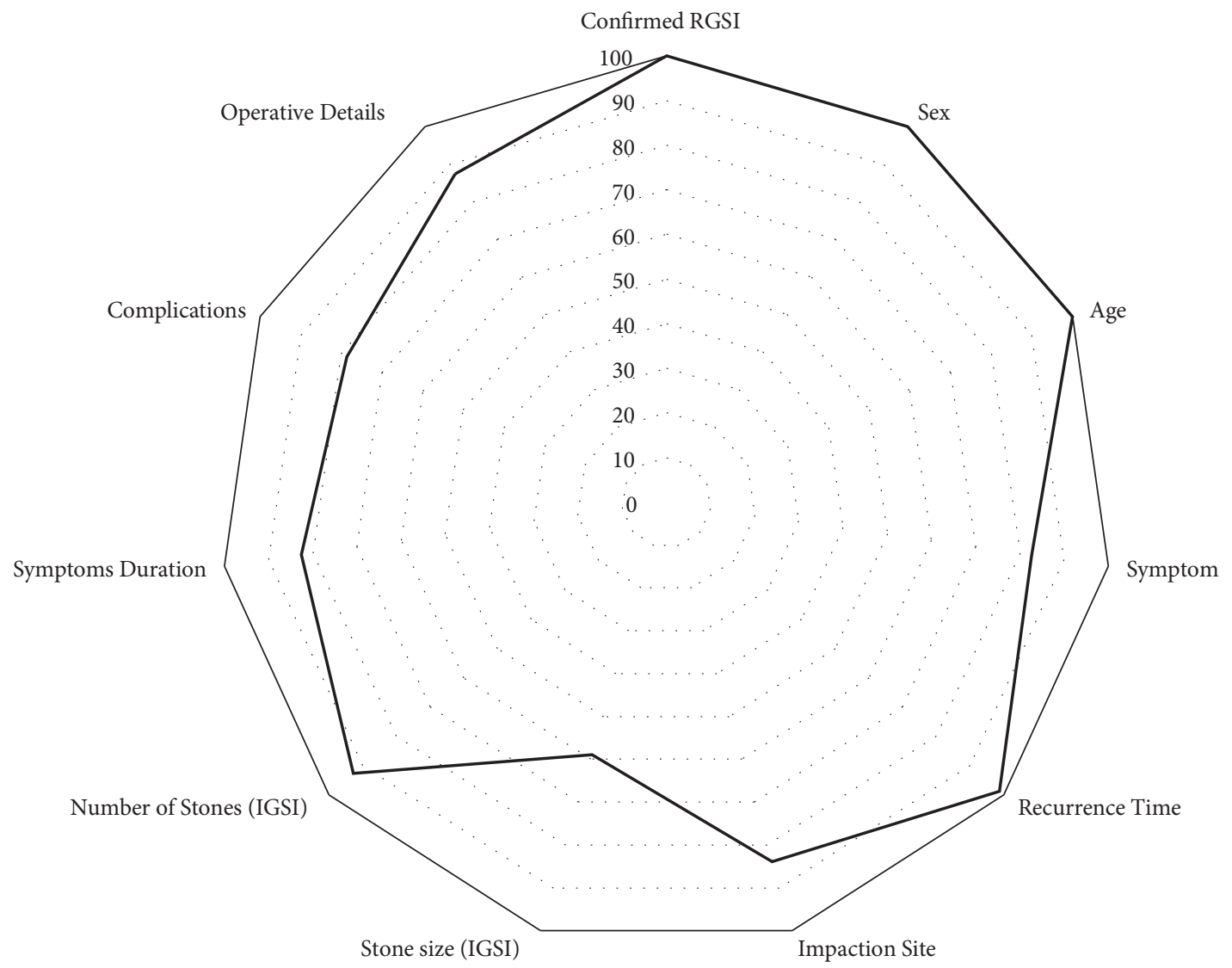

FIgURE 2: Completeness of data extraction.

3.5. Regularity of the SOI. For 45 patients, matched data for SOI were available in IGSI and RGSI. In 11 of 16 cases $(68.8 \%)$, in which ISOI was the jejunum, RSOI was also the jejunum. Furthermore, in 22 of 27 cases $(81.5 \%)$ in which ISOI was the ileum, RSOI was also in the ileum $(p=0.002$, Figure 4 and Table 2).

A logistic regression analysis was performed to investigate the likely effect of various parameters observed during IGSI on RSOI (ileum); the variables used in the analysis were large stones at IGSI, single versus more than one stone during IGSI, age, ISOI (ileum), and sex. None of the variables except ISOI (ileum) had a statistically significant association with the RSOI (ileum) in univariate analysis. Multiple stepwise logistic regression was performed for large stones, sex, and ISOI (ileum). The overall model correctly predicted $84.6 \%$ of the cases. Only ISOI (ileum) was found to have a significant association with RSOI (ileum) (odds ratio: 36.5, 95\% confidence interval (CI): 2.5-532.6, $p=0.009$, Table 3). The $p$ value for the Hosmer-Lemeshow goodnessof-fit statistic was 0.56 , and the area under the ROC curve was 0.884 .

\section{Discussion}

This study presented the first meta-analysis of RGSI. This analysis provided information on the key aspects of RGSI, such as SOI in IGSI and RGSI, the pattern of surgical interventions, age- and sex-stratified analysis, the correlation between age and recurrence time, mortality, and morbidity. A systematic review of RGSI is available in cases reported up to April 2015 [12]; however, a pooled analysis of important characteristics of RGSI is missing from the literature. This study complements, extends, and updates the previous systematic review by conducting a meta-analysis of case reports.

Currently, there are no standard guidelines for the management of GSI. When GSI recurs, the dilemmas associated with its management become considerably more complicated because the patient has already undergone surgery $[1,4,6,7,12,22,23,25,62-65]$. In most cases, the recurrence happens within a few days of the IGSI; thus, there is not much time between index admission and readmission for the patient's physical and psychological recuperation. The pooled mortality rate in RGSI was determined to be $11.8 \%$ in this study. Age is frequently seen as a risk factor for mortality and surgical complications [18]; however, this study did not observe an increased propensity to mortality or morbidity in patients in relatively higher age groups. These findings do not necessarily rule out the possibility of a risk associated with advanced age or a surgical procedure; however, they may indicate that the respective surgeons have already implemented appropriate care and surgical selection, which take into account the risks associated with age and surgery, resulting in minimal age-group-dependent variations in mortality and morbidity [66]. Notably, due to the high rate of postoperative morbidity and mortality in a 
TABLE 1: Demographic and clinical characteristics of patients.

\begin{tabular}{|c|c|c|}
\hline & Variable & \#Summary $n(\%)$ or median $(\mathrm{Q} 1, \mathrm{Q} 3)$ \\
\hline \multirow{14}{*}{ IGSI } & ISOI $(N=47)$ & \\
\hline & Jejunum & $16(34.0 \%)$ \\
\hline & Ileum & $29(61.7 \%)$ \\
\hline & Others & $2(4.3 \%)$ \\
\hline & Stone $\geq 3 \mathrm{~cm}(N=33)$ & $25(75.8 \%)$ \\
\hline & Faceted stone $(N=18)$ & $12(66.7 \%)$ \\
\hline & Number of stones $(N=52)$ & \\
\hline & One & $41(78.8 \%)$ \\
\hline & Two & $8(15.4 \%)$ \\
\hline & More than two & $3(5.8 \%)$ \\
\hline & Surgery $(N=51)$ & \\
\hline & Enterolithotomy & $42(82.4 \%)$ \\
\hline & Enterolithotomy + segmental resection & $5(9.8 \%)$ \\
\hline & Others & $4(7.8 \%)$ \\
\hline \multirow{20}{*}{ RGSI } & Time of recurrence (days) $(N=56)$ & $20.5(8.5,95.5)$ \\
\hline & RSOI $(N=50)$ & \\
\hline & Jejunum & $15(30.0 \%)$ \\
\hline & Ileum & $31(62.0 \%)$ \\
\hline & Others & $4(8.0 \%)$ \\
\hline & Age (years) $(N=55)$ & $70.0(63.0,76.0)$ \\
\hline & Sex (women) $(N=55)$ & $48(87.3 \%)$ \\
\hline & Symptoms (RGSI) $(N=47)$ & \\
\hline & Abdominal pain & $44(93.6 \%)$ \\
\hline & Vomit & $38(80.9 \%)$ \\
\hline & Nausea & $16(34.0 \%)$ \\
\hline & Constipation & $5(10.6 \%)$ \\
\hline & Symptom duration (RGSI) $(N=18)$ & $2.5(1.0,7.0)$ \\
\hline & Surgery $(\mathrm{RGSI})(N=53)$ & \\
\hline & Enterolithotomy & $42(79.2 \%)$ \\
\hline & Enterolithotomy + cholecystectomy & $5(9.4 \%)$ \\
\hline & Enterolithotomy + segmental resection & $2(3.8 \%)$ \\
\hline & Others & $4(7.5 \%)$ \\
\hline & Mortality (RGSI) $(N=51)$ & $6(11.8 \%)$ \\
\hline & Complications (RGSI) $(N=46)$ & $13(28.3 \%)$ \\
\hline
\end{tabular}

"Continuous variables are presented as median and IQR and categorical variables as number $(n)$ and (percentage); $N$ represents the total number of patients for whom the data was available for that particular variable; IQR: interquartile range; GSI: gallstone ileus; RGSI: recurrent gallstone ileus; IGSI: index gallstone ileus; ISOI: site of impaction in index gallstone ileus; RSOI: site of impaction in recurrent gallstone ileus.

single-step approach (enterolithotomy + cholecystectomy)), most surgeons prefer the enterolithotomy only approach in GSI [6, 9, 12, 22, 23, 25, 64, 66-69].

This study also indicated that most of the patients with RGSI were women, which confirms that women are at a higher risk for RGSI. The ileum was the SOI most frequently observed in both IGSI and RGSI. This observation is consistent with other findings [5, 23, 31, 34, 35, 63, 67, 70-73]. However, one notable aspect was that SOI was identical in approximately $70 \%$ of cases in IGSI and RGSI; that is, in RGSI, the ileum was not the predominant SOI in patients who had impaction at the jejunum in IGSI. Multivariate logistic regression also confirmed these findings. It should also be noted that there were no statistically significant differences between SOI and the observed incidence of large stones. More research is needed to substantiate our findings; however, when there is a suspicion of RGSI, it may be beneficial to focus on the region where the stone was impacted in the IGSI. Given the dilemma of diagnosing and managing emergencies in RGSI, such a method may provide a practical advantage.

Conservative management was adopted in only four cases. RSOI was the rectum in two of these cases [56,57], and in one case, SOI was the duodenum and the management approach involved Holmium: YAG laser lithotripsy [31]. RGSI is often treated with enterolithotomy or with cholecystectomy and repair of the enteric biliary fistula $[72,74,75]$. Our analysis found that enterolithotomy was the procedure most commonly used in approximately $82 \%$ and $80 \%$ of cases at IGSI and RGSI, respectively. Furthermore, SOI had little effect on the surgical procedures chosen, demonstrating a common predilection for enterolithotomy $[1,6,7,24,27,69,76]$.

The current systematic review provides the first metaanalysis and the most up-to-date state of the epidemiological and clinical aspects of RGSI. The cases included in this paper were identified by a thorough search of the major databases using the PRISMA approach, and only case reports with 


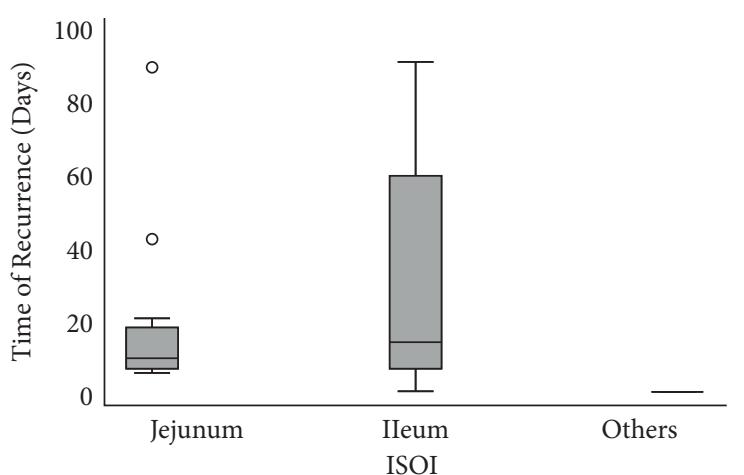

(a)

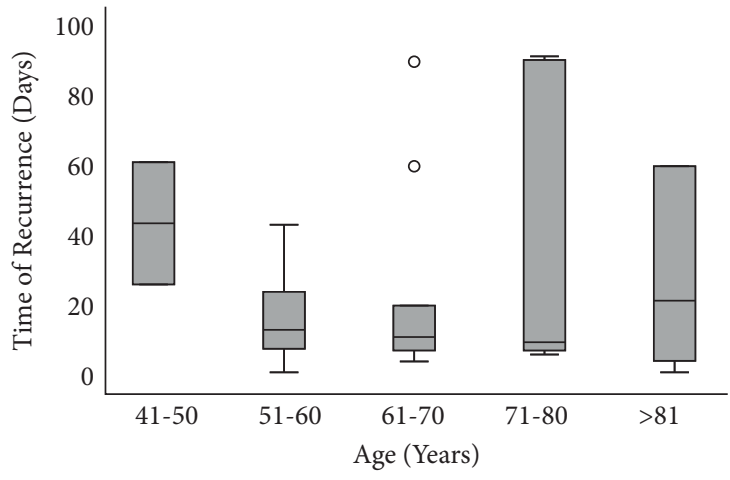

(c)

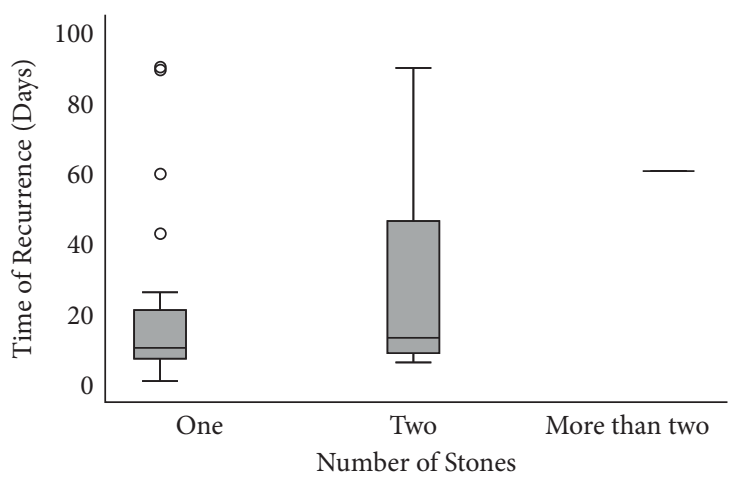

(b)

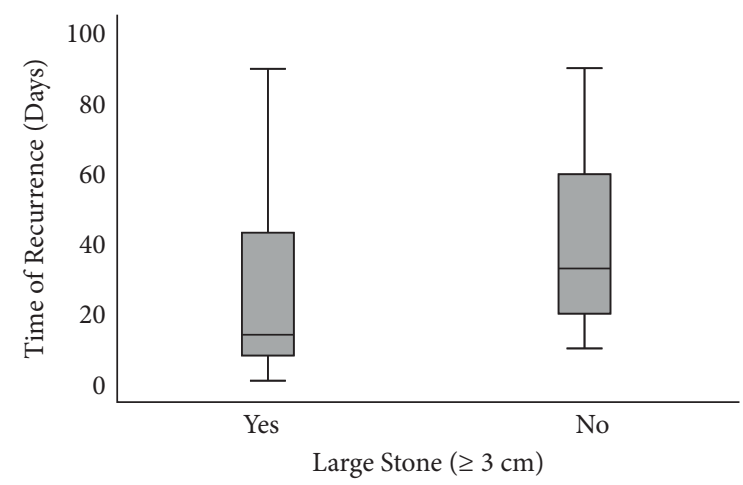

(d)

Figure 3: Time of recurrence, (a) ISOI ( $p=0.73)$, (b) number of stones $(p=0.27)$, (c) age groups in years $(p=0.96)$, and (d) size of stones $(p=0.18)$.

TABLE 2: ISOI and clinical characteristics of patients in IGSI and RGSI.

\begin{tabular}{|c|c|c|c|c|c|c|}
\hline & \multirow{2}{*}{ Variable } & \multicolumn{4}{|c|}{ ISOI } & \multirow{2}{*}{$p$ value } \\
\hline & & Jejunum & Ileum & Others & Total & \\
\hline \multirow{14}{*}{ IGSI } & Stone $\geq 3 \mathrm{~cm}(N=32)$ & & & & & 0.730 \\
\hline & Yes & $9(75.0 \%)$ & $14(77.8 \%)$ & $2(100.0 \%)$ & $25(78.1 \%)$ & \\
\hline & No & $3(25.0 \%)$ & $4(22.2 \%)$ & $0(0.0 \%)$ & $7(21.9 \%)$ & \\
\hline & Faceted stone $(N=17)$ & & & & & 0.602 \\
\hline & Yes & $5(71.4 \%)$ & $5(55.6 \%)$ & $1(100.0 \%)$ & $11(64.7 \%)$ & \\
\hline & No & $2(28.6 \%)$ & $4(44.4 \%)$ & $0(0.0 \%)$ & $6(35.3 \%)$ & \\
\hline & Number of stones $(N=46)$ & & & & & 0.670 \\
\hline & One & $14(87.5 \%)$ & $22(78.6 \%)$ & $2(100.0 \%)$ & $38(82.6 \%)$ & \\
\hline & Two & $2(12.5 \%)$ & $3(10.7 \%)$ & $0(0.0 \%)$ & $5(10.9 \%)$ & \\
\hline & More than two & $0(0.0 \%)$ & $3(10.7 \%)$ & $0(0.0 \%)$ & $3(6.5 \%)$ & \\
\hline & Surgery $(N=44)$ & & & & & \\
\hline & Enterolithotomy & $14(87.5 \%)$ & $23(88.5 \%)$ & $1(50.0 \%)$ & $38(86.4 \%)$ & \\
\hline & Enterolithotomy + segmental resection & $2(12.5 \%)$ & $3(11.5 \%)$ & $0(0.0 \%)$ & $5(11.4 \%)$ & \\
\hline & Others & $0(0.0 \%)$ & $0(0.0 \%)$ & $1(50.0 \%)$ & $1(2.3 \%)$ & \\
\hline
\end{tabular}


TABLE 2: Continued.

\begin{tabular}{|c|c|c|c|c|c|c|}
\hline & \multirow{2}{*}{ Variable } & \multicolumn{4}{|c|}{ ISOI } & \multirow{2}{*}{$p$ value } \\
\hline & & Jejunum & Ileum & Others & Total & \\
\hline \multirow{24}{*}{ RGSI } & $\operatorname{Sex}(N=47)$ & & & & & 0.852 \\
\hline & Men & $2(12.5 \%)$ & $4(13.8 \%)$ & $0(0.0 \%)$ & $6(12.8 \%)$ & \\
\hline & Women & $14(87.5 \%)$ & $25(86.2 \%)$ & $2(100.0 \%)$ & $41(87.2 \%)$ & \\
\hline & Age (years) $(N=47)$ & $71.5(65.0,76.0)$ & $69.0(67.0,76.0)$ & $59.0(55.0,63.0)$ & $70.0(65.0,76.0)$ & 0.200 \\
\hline & Time of recurrence $(N=47)$ & $15.0(7.5,97.5)$ & $26.0(9.0,91.0)$ & $50.4(0.8,100.0)$ & $20.0(8.0,100.0)$ & 0.738 \\
\hline & Symptoms $(N=41)$ & & & & & \\
\hline & Abdominal pain & & & & & 0.903 \\
\hline & Yes & $14(93.3 \%)$ & $22(91.7 \%)$ & $2(100.0 \%)$ & $38(92.7 \%)$ & \\
\hline & No & $1(6.7 \%)$ & $2(8.3 \%)$ & $0(0.0 \%)$ & $3(7.3 \%)$ & \\
\hline & Vomit & & & & & 0.520 \\
\hline & Yes & $13(86.7 \%)$ & $18(75.0 \%)$ & $2(100.0 \%)$ & $33(80.5 \%)$ & \\
\hline & No & $2(13.3 \%)$ & $6(25.0 \%)$ & $0(0.0 \%)$ & $8(19.5 \%)$ & \\
\hline & RSOI $(N=45)$ & & & & & 0.002 \\
\hline & Jejunum & $11(68.8 \%)$ & $3(11.1 \%)$ & $0(0.0 \%)$ & $14(31.1 \%)$ & \\
\hline & Ileum & $4(25.0 \%)$ & $22(81.5 \%)$ & $2(100.0 \%)$ & $28(62.2 \%)$ & \\
\hline & Others & $1(6.3 \%)$ & $2(7.4 \%)$ & $0(0.0 \%)$ & $3(6.7 \%)$ & \\
\hline & Stone $\geq 3 \mathrm{~cm}(N=31)$ & & & & & 0.028 \\
\hline & Yes & $7(53.8 \%)$ & $15(93.8 \%)$ & $2(100.0 \%)$ & $24(77.4 \%)$ & \\
\hline & No & $6(46.2 \%)$ & $1(6.3 \%)$ & $0(0.0 \%)$ & $7(22.6 \%)$ & \\
\hline & Surgery $(N=45)$ & & & & & 0.994 \\
\hline & Enterolithotomy & $13(81.3 \%)$ & $23(85.2 \%)$ & $2(100.0 \%)$ & $38(84.4 \%)$ & \\
\hline & Enterolithotomy + cholecystectomy & $1(6.3 \%)$ & $2(7.4 \%)$ & $0(0.0 \%)$ & $3(6.7 \%)$ & \\
\hline & Enterolithotomy + segmental resection & $1(6.3 \%)$ & $1(3.7 \%)$ & $0(0.0 \%)$ & $2(4.4 \%)$ & \\
\hline & Others & $1(6.3 \%)$ & $1(3.7 \%)$ & $0(0.0 \%)$ & $2(4.4 \%)$ & \\
\hline
\end{tabular}

\#Continuous variables are presented as median and IQR and categorical variables as number $(n)$ and percentage; $N$ represents the total number of patients for whom data were available for that particular variable; IGSI: index gallstone ileus; RGSI: recurrent gallstone ileus; ISOI: site of impaction in index gallstone ileus; RSOI: site of impaction in RGSI; categorical variables were examined by the chi-square test and continuous variables by the Kruskal-Wallis test.

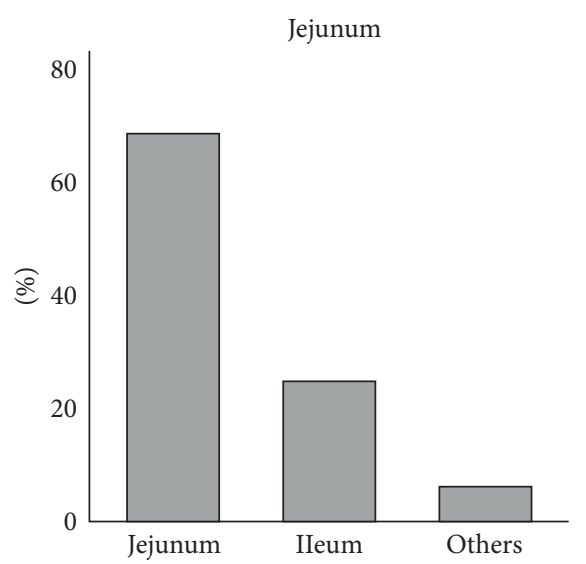

(a)

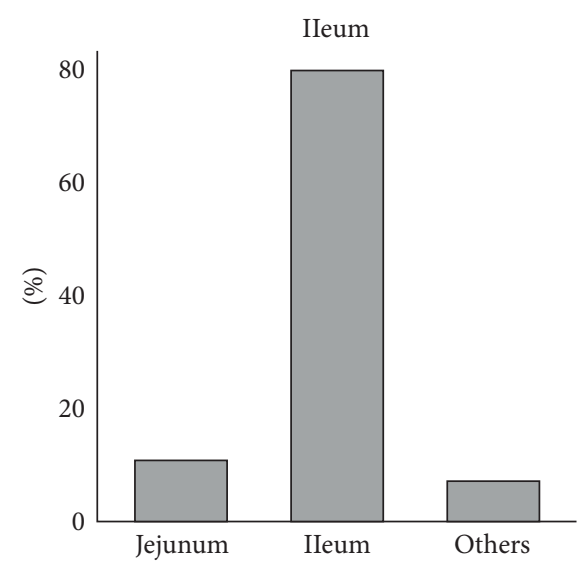

(b)

FIGURE 4: Impaction sites in RGSI patients, (a) with impaction in the jejunum during IGSI and (b) with impaction in the ileum during IGSI.

good reporting standards were included. However, despite carefully applying a rigorous inclusion criterion, it is impossible to rule out the possibility of missing some cases aggregated in case series, those that were not published in English, or those reported in conference abstract or letter to the editor. Furthermore, patients with missing data were excluded from the analysis, further limiting the generalizability of the synthesized data. Publication bias, which is generally observed in the publication of a case report, can also affect the generalizability of our results. Furthermore, the cases reported in the analysis cover a broad period; therefore, temporal variations with advances in diagnostic modalities and treatment and their corresponding impact on clinical outcomes are quite probable. Such factors should be considered before generalizing the results. It may be noted that, generally, the rarest and clinically challenging cases are reported and accepted as case reports; therefore, common or less significant cases may be underrepresented. A lower 
TABLE 3: Logistic regression analysis of the factors affecting the risk of RSOI (ileum).

\begin{tabular}{|c|c|c|c|c|c|c|c|c|}
\hline \multirow{3}{*}{ Variable } & \multirow{3}{*}{ OR } & Univar & nalysis & \multirow{3}{*}{$p$ value } & \multirow{3}{*}{ OR } & \multirow{2}{*}{\multicolumn{2}{|c|}{$\begin{array}{c}\text { Multivariate } \\
\text { analysis } \\
95 \% \text { CI }\end{array}$}} & \multirow{3}{*}{$p$ value } \\
\hline & & \multicolumn{2}{|c|}{$95 \% \mathrm{CI}$} & & & & & \\
\hline & & Lower & Upper & & & Lower & Upper & \\
\hline Large stone (IGSI) & 0.19 & 0.03 & 1.30 & 0.091 & 0.17 & 0.01 & 3.01 & 0.225 \\
\hline Sex (women) & 1.44 & 0.21 & 9.66 & 0.37 & 8.35 & 0.21 & 324.6 & 0.256 \\
\hline Number of stones (IGSI) & 1.03 & 0.30 & 3.57 & 0.97 & & & & \\
\hline Age & 0.98 & 0.93 & 1.04 & 0.543 & & & & \\
\hline ISOI (ileum) & 20.2 & 3.8 & 106.4 & $<0.001$ & 36.5 & 2.50 & 532.6 & 0.009 \\
\hline
\end{tabular}

The area under the ROC curve: 0.884 ; Hosmer-Lemeshow goodness-of-fit statistic $p$ value $=0.56$; multicollinearity was not found among the independent variables used for multivariate analysis. RSOI: site of impaction at the RGSI; RGSI: recurrent gallstone ileus; OR: odds ratio; CI: confidence interval; ISOI: site of impaction at the IGSI; IGSI: index gallstone ileus.

number of cases also caution the generalization of the results reported in this work. Despite these limitations, the results of this meta-analysis reveal more nuanced details of patients with RGSI, which may help in the management of this rare and high-risk condition.

\section{Conclusions}

The findings of this meta-analysis have helped to determine various unexplored aspects of RGSI. Particularly notable findings are that more than 60-year-old women represent most cases of RGSI, and SOI in IGSI and RGSI are frequently similar. Recurrence time is not correlated with age or with ISOI, stone size at IGSI, or sex. Future research should focus on the pathophysiology of stone formation, migration dynamics, and identifiable anatomical features of the small intestine.

\section{Data Availability}

The data used to support the findings of this study are available from the corresponding author upon request.

\section{Conflicts of Interest}

The authors declare that they have no conflicts of interest.

\section{Authors' Contributions}

N. Alzerwi designed the study, conducted the literature search, extracted the data, analyzed the data, and wrote the manuscript. B. Idrees conducted the literature search, extracted the data, and wrote the manuscript. S. Alsareii conducted the literature search and extracted the data. A. Alsultan conducted the literature search and extracted the data. Y. Aldebasi conducted the literature search and extracted the data.

\section{Acknowledgments}

The authors express their gratitude to their colleagues for their assistance in identifying and addressing discrepancies in study selection and data extraction. The authors thank the Deanship of Scientific Research at Majmaah University for supporting this work.

\section{Supplementary Materials}

Supplementary tables include details of PRISMA checklist, surgery type, mortality, adverse events at RGSI, and demographics and clinical features of patients in different age groups. Supplementary figures include figures related to spread of time of recurrence (days), spread of symptoms duration (days), and correlation between age and time of recurrence (days). (Supplementary Materials)

\section{References}

[1] L. H. Webb, M. M. Ott, and O. L. Gunter, "Once bitten, twice incised: recurrent gallstone ileus," The American Journal of Surgery, vol. 200, no. 6, pp. e72-e74, 2010.

[2] N. Farkas, V. Kaur, A. Shanmuganandan et al., "A systematic review of gallstone sigmoid ileus management," Annals of Medicine and Surgery, vol. 27, pp. 32-39, 2018.

[3] K. Inukai, "Gallstone ileus: a review," BMJ Open Gastroenterology, vol. 6, no. 1, Article ID e000344, 2019.

[4] D. S. Kalwaniya, S. V. Arya, S. Guha et al., "A rare presentation of gastric outlet obstruction (GOO)-the bouveret's syndrome," Annals of Medicine and Surgery, vol. 4, no. 1, pp. 67-71, 2015.

[5] T. A. Gandamihardja and S. M. Kibria, "Recurrent gallstone ileus: beware of the faceted stone," BMJ Case Reports, vol. 2014, 2014.

[6] P. G. Vaughan-Shaw and A. Talwar, "Gallstone ileus and fatal gallstone coleus: the importance of the second stone," BMJ Case Reports, vol. 2013, 2013.

[7] N. E. Williams, J. S. Gundara, S. Roser, and J. S. Samra, "Disease spectrum and use of cholecystolithotomy in gallstone ileus," Hepatobiliary \& Pancreatic Diseases International, vol. 11, no. 5, pp. 553-557, 2012.

[8] J. E. F. Fitzgerald, L. A. Fitzgerald, C. A. Maxwell-Armstrong, and A. J. Brooks, "Recurrent gallstone ileus: time to change our surgery?" Journal of Digestive Diseases, vol. 10, no. 2, pp. 149-151, 2009.

[9] W. Kirchmayr, G. Mühlmann, M. Zitt, J. Bodner, H. Weiss, and A. Klaus, "Gallstone ileus: rare and still controversial," ANZ Journal of Surgery, vol. 75, no. 4, pp. 234-238, 2005.

[10] R. G. Syme, "Management of gallstone ileus," Canadian Journal of Surgery. Journal Canadien de Chirurgie, vol. 32, no. 1, pp. 61-64, 1989.

[11] A. U. Haq, A. H. Morris, and H. Daintith, "Recurrent gallstone ileus," The British Journal of Radiology, vol. 54, no. 647, pp. 1000-1001, 1981. 
[12] S. A. Mir, Z. Hussain, C. A. Davey, G. V. Miller, and S. Chintapatla, "Management and outcome of recurrent gallstone ileus: a systematic review," World Journal of Gastrointestinal Surgery, vol. 7, no. 8, pp. 152-159, 2015.

[13] A. Liberati, D. G. Altman, J. Tetzlaff et al., "The PRISMA statement for reporting systematic reviews and meta-analyses of studies that evaluate healthcare interventions: explanation and elaboration," BMJ, vol. 339, Article ID b2700, 2009.

[14] M. H. Murad, S. Sultan, S. Haffar, and F. Bazerbachi, "Methodological quality and synthesis of case series and case reports," BMJ Evidence-Based Medicine, vol. 23, no. 2, pp. 60-63, 2018.

[15] J. J. Gagnier, G. Kienle, D. G. Altman et al., "The CARE guidelines: consensus-based clinical case reporting guideline development," Journal of Medical Case Reports, vol. 7, no. 1, p. 223, 2013.

[16] A. B. Lowenfels, A. M. Walker, D. P. Althaus, G. Townsend, and L. Domellöf, "Gallstone growth, size, and risk of gallbladder cancer: an interracial study," International Journal of Epidemiology, vol. 18, no. 1, pp. 50-54, 1989.

[17] M. H. Freeman, M. G. Mullen, and C. M. Friel, “The Progression of cholelithiasis to gallstone ileus: do large gallstones warrant surgery?" Journal of Gastrointestinal Surgery, vol. 20, no. 6, pp. 1278-1280, 2016.

[18] O. Osagiede, P. Pacurari, D. Colibaseanu, and N. Jrebi, "Unusual presentation of recurrent gallstone ileus: a case report and literature review," Case Reports in Gastrointestinal Medicine, vol. 2019, Article ID 8907068, 4 pages, 2019.

[19] A. Iudicello, J. Vanstiphout, and T. Verbelen, "Recurrent gallstone ileus," Acta Chirurgica Belgica, vol. 116, no. 3, pp. 184-186, 2016.

[20] H. Takata, H. Yoshida, A. Hirakata, M. Watanabe, E. Uchida, and E. Uchida, "Recurrent gallstone ileus successfully treated with conservative therapy," Journal of Nippon Medical School, vol. 82, no. 6, pp. 300-303, 2015.

[21] J. R. Apollos and R. V. Guest, "Recurrent gallstone ileus due to a residual gallstone: a case report and literature review," International Journal of Surgery Case Reports, vol. 13, pp. 12-14, 2015.

[22] J. Aslam, P. Patel, and S. Odogwu, "A case of recurrent gallstone ileus: the fate of the residual gallstone remains unknown," BMJ Case Reports, vol. 2014, 2014.

[23] A. Pronio, S. Piroli, D. Caporilli et al., "Recurrent gallstone ileus: case report and literature review," Il Giornale di Chirurgia, vol. 34, no. 1-2, pp. 35-37, 2013.

[24] R. Jones, D. Broman, R. Hawkins, and D. Corless, "Twice recurrent gallstone ileus: a case report," Journal of Medical Case Reports, vol. 6, no. 1, p. 362, 2012.

[25] N. Hayes and S. Saha, "Recurrent gallstone ileus," Clinical Medicine \& Research, vol. 10, no. 4, pp. 236-239, 2012.

[26] S. Shenoy and R. Cassim, "Recurrent gallstone ileus with hostile right upper quadrant: a surgeon's dilemma," The American Surgeon, vol. 76, no. 5, pp. E26-E27, 2010.

[27] Z. Hussain, M. S. Ahmed, D. J. Alexander, G. V. Miller, and S. Chintapatla, "Recurrent recurrent gallstone ileus," Annals of the Royal College of Surgeons of England, vol. 92, no. 5, pp. W4-W6, 2010.

[28] J. M. Suárez Grau, C. Rubio Cháves, I. Alarcón del Agua et al., "[Gallstone ileus recurrence]," Revista Española de Enfermedades Digestivas: Organo Oficial de la Sociedad Espanola de Patologia Digestiva, vol. 101, no. 3, pp. 223-225, 2009.

[29] P. A. Vagefi, C. M. Ferguson, and J. F. Hall, "Recurrent gallstone ileus: third time is the charm," Archives of Surgery (Chicago, Ill: 1960, vol. 143, no. 11, pp. 1118-1120, 2008.
[30] R. Zissin, A. Osadchy, E. Klein, and F. Konikoff, "Consecutive instances of gallstone ileus due to obstruction first at the ileum and then at the duodenum complicating a gallbladder carcinoma: a case report," Emergency Radiology, vol. 12, no. 3, pp. 108-110, 2006.

[31] E. B. Goldstein, R. H. Savel, H. L. Pachter, J. Cohen, and P. Shamamian, "Successful treatment of bouveret syndrome using holmium: YAG laser lithotripsy," The American Surgeon, vol. 71, no. 10, pp. 882-885, 2005.

[32] S. Guttikonda, K. K. Vaswani, and K. M. Vitellas, "Recurrent gallstone ileus: a case report," Emergency Radiology, vol. 9, no. 2, pp. 110-112, 2002.

[33] J. B. Davies, P. C. Sedman, and E. A. Benson, "Gallstone ileus-beware the silent second stone," Postgraduate Medical Journal, vol. 72, no. 847, pp. 300-301, 1996.

[34] J. C. Pangan, R. Estrada, and R. Rosales, "Cholecystoduodenocolic fistula with recurrent gallstone ileus," Archives of Surgery (Chicago, Ill: 1960, vol. 119, no. 10, pp. 1201-1203, 1984.

[35] B. Levin and R. A. Shapiro, "Recurrent enteric gallstone obstruction," Gastrointestinal Radiology, vol. 5, no. 2, pp. 151-153, 1980.

[36] S. Ulreich and J. Massi, "Recurrent gallstone ileus," American Journal of Roentgenology, vol. 133, no. 5, pp. 921-923, 1979.

[37] G. R. Meng, "Recurrent gallstone intestinal obstruction with bacterial enteritis proximal to obstruction-a case report," Military Medicine, vol. 135, no. 10, pp. 909-911, 1970.

[38] A. M. Cooperman, E. R. Dickson, and W. H. ReMine, "Changing concepts in the surgical treatment of gallstone ileus: a review of 15 cases with emphasis on diagnosis and treatment," Annals of Surgery, vol. 167, no. 3, pp. 377-383, 1968.

[39] R. A. Malt, "Experience with recurrent gallstone ileus applied to management of the first attack," The American Journal of Surgery, vol. 108, no. 1, pp. 92-94, 1964.

[40] H. S. Thomas, J. K. Cherry, B. D. Averbook, and G. Ileus, "Gallstone ileus," JAMA: The Journal of the American Medical Association, vol. 179, no. 8, pp. 625-629, 1962.

[41] J. Logie, H. Bishop, D. Bullington et al., "Chronic benign penetrating lesions of the gallbladder," Annals of Surgery, vol. 154, no. Suppl 6, p. 121, 1961.

[42] K. C. Kirkland and E. J. Croce, "Gallstone intestinal obstruction: a review of the literature and presentation of 12 cases, including 3 recurrences," JAMA: The Journal of the American Medical Association, vol. 176, no. 6, pp. 494-497, 1961.

[43] M. Claridge, "Recurrent gall-stone ileus," The British Journal of Surgery, vol. 49, pp. 134-135, 1961.

[44] R. V. Fiddian and G. S. Ileus, "Recurrences and multiple stones," Postgraduate Medical Journal, vol. 35, no. 410, pp. 673-676, 1959.

[45] F. A. Rogers and R. Carter, "Recurrent gallstone ileus," The American Journal of Surgery, vol. 96, no. 3, pp. 379-386, 1958.

[46] J. G. Brockis and M. C. Gilbert, "Intestinal obstruction by gallstones; a review of 179 cases," The British Journal of Surgery, vol. 44, no. 187, pp. 461-466, 1957.

[47] S. Shore, H. H. Jacob, and J. A. Cannon, "Intestinal obstruction resulting from biliary calculi gallstone ileus," $A r$ chives of Surgery, vol. 66, no. 3, pp. 301-311, 1953.

[48] J. A. Macfarlane, "Recurrent gall-stone ileus," British Medical Journal, vol. 2, no. 4835, pp. 544-545, 1953.

[49] E. Milch, "Recurrent gallstone small bowel obstruction," Archives of Surgery, vol. 64, no. 6, pp. 847-850, 1952. 
[50] M. Lee, "Intestinal obstruction by gall-stones," British Medical Journal, vol. 1, no. 4398, pp. 555-556, 1945.

[51] B. H. Hand and W. E. Gilmore, "Gallstone ileus: recurrence in one case," The American Journal of Surgery, vol. 59, no. 1, pp. 72-78, 1943.

[52] H. L. Foss and J. D. Summers, "Intestinal obstruction from gallstones," Annals of Surgery, vol. 115, no. 5, pp. 721-735, 1942.

[53] P. R. Hinchey, "Recurrent gallstone ileus," New England Journal of Medicine, vol. 223, no. 5, pp. 174-179, 1940.

[54] W. H. Mast, "Recurrent intestinal obstruction due to gallstone," The American Journal of Surgery, vol. 32, no. 3, pp. 516-518, 1936.

[55] C. P. G. Wakeley and F. W. Willway, "Intestinal obstruction by gall-stones," British Journal of Surgery, vol. 23, no. 90, pp. 377-394, 1935.

[56] A. Van Ravenswaay, "Acute intestinal obstruction by large gallstone," The American Journal of Surgery, vol. 16, no. 1, p. 56, 1932.

[57] P. H. Cook and R. P. Watkins, "Recurring intestinal obstruction by gall stone," New England Journal of Medicine, vol. 207, no. 10, pp. 462-465, 1932.

[58] J. Douglas, "Transactions of the New York surgical societystated meeting January 27, 1932," Annals of Surgery, vol. 96, no. 1, pp. 107-117, 1932.

[59] G. G. Turner, "Intestinal obstruction from gall-stone: "gallstone ileus.", Postgraduate Medical Journal, vol. 2, no. 17, pp. 65-73, 1927.

[60] F. Pybus, "A note on two cases of gall-stone ileus," The Lancet, vol. 200, no. 5172, pp. 812-813, 1922.

[61] Transactions of the New York Surgical Society, "Stated meeting, held at the Mt. sinai hospital, January 10, 1912," Annals of Surgery, vol. 55, no. 4, pp. 598-617, 1912.

[62] F. Stagnitti, A. Tudisco, F. Ceci et al., "Biliodigestive fistulae and gallstone ileus: diagnostic and therapeutic considerations. our experience," Il Giornale di Chirurgia, vol. 35, no. 9-10, pp. 235-238, 2014.

[63] C. Toelen and M. Huyghe, "Gallstone ileus in a patient with crohn's disease: a case report," Acta Chirurgica Belgica, vol. 112, no. 5, pp. 390-392, 2012.

[64] I. Ivanov, M. Beuran, M. D. Venter et al., "Gallstone ileus after laparoscopic cholecystectomy," Journal of Medicine and Life, vol. 5, no. 3, pp. 335-341, 2012.

[65] F. Zingales, E. Pizzolato, M. Menegazzo, C. Da Re, and R. Bardini, "Gallstone ileus of the sigmoid colon: a rare complication of cholelithiasis," Updates in Surgery, vol. 63, no. 3, pp. 219-221, 2011.

[66] M. K. Mallipeddi, T. N. Pappas, M. L. Shapiro, and J. E. Scarborough, "Gallstone ileus: revisiting surgical outcomes using national surgical quality improvement program data," Journal of Surgical Research, vol. 184, no. 1, pp. 84-88, 2013.

[67] H. K. Lamba, Y. Shi, and A. Prabhu, "Gallstone ileus associated with impaction at meckel's diverticulum: case report and literature review," World Journal of Gastrointestinal Surgery, vol. 8, no. 11, pp. 755-760, 2016.

[68] G. Muthukumarasamy, S. P. Venkata, I. A. Shaikh, B. K. Somani, and R. Ravindran, "Gallstone ileus: surgical strategies and clinical outcome," Journal of Digestive Diseases, vol. 9, no. 3, pp. 156-161, 2008.

[69] L. Wang, P. Dong, Y. Zhang, and B. Tian, "Gallstone ileus displaying the typical rigler triad and an occult second ectopic stone: a case report," Medicine, vol. 96, no. 45, Article ID e8541, 2017.
[70] E. I. Efremidou, N. Liratzopoulos, M. S. Papageorgiou, G. Kouklakis, G. J. Minopoulos, and K. J. Manolas, "Enterolith small-bowel obstruction caused by jejunal diverticulosis: report of a case," Surgery Today, vol. 36, no. 11, pp. 1003-1006, 2006.

[71] J. J. He, K. Q. Xu, and J. H. Tang, "[Intestinal obstruction caused by gallstone: report of 5 cases and review of the literature]," Zhonghua Wei Chang Wai ke Za Zhi = Chinese Journal of Gastrointestinal Surgery, vol. 13, no. 10, pp. 751754, 2010.

[72] H. Jiang, C. Jin, J. G. Mo, L. Z. Wang, L. Ma, and K. P. Wang, "Rare recurrent gallstone ileus: a case report," World Journal of Clinical Cases, vol. 8, no. 10, pp. 2023-2027, 2020.

[73] G. M. Senofsky and B. E. Stabile, "Gallstone ileus associated with crohn's disease," Surgery, vol. 108, no. 1, pp. 114-117, 1990.

[74] A. Pezzoli, A. Maimone, N. Fusetti, and E. Pizzo, "Gallstone ileus treated with non-surgical conservative methods: a case report," Journal of Medical Case Reports, vol. 9, no. 1, p. 15, 2015.

[75] S. Umer, U. I. Butt, A. A. Toor et al., "Gallstone Ileus with cholecysto-duodenal fistula in an elderly male," Journal of Ayub Medical College, Abbottabad: JAMC, vol. 30, no. 4, pp. 614-416, 2018.

[76] W. J. Halabi, C. Y. Kang, N. Ketana et al., "Surgery for gallstone ileus: a nationwide comparison of trends and outcomes," Annals of Surgery, vol. 259, no. 2, pp. 329-335, 2014. 